\title{
Mucocele-Like Tumor of the Breast Associated with Ductal Carcinoma In Situ and Mucinous Carcinoma
}

\section{: A Case Report}

\begin{abstract}
Mucocele-like tumor (MLT) of the breast is a rare neoplasm. Although this lesion was considered benign when first described, the concept of a pathologic continuum with mucinous carcinoma was evident in subsequent reports. Only a few cases of MLT have been reported in Korea. We describe a case of MLT associated with ductal carcinoma in situ and mucinous carcinoma in a 34-yr-old female. Histological examination showed multiple mucus-filled cysts of varying size. Extravasated mucin was present in the surrounding stroma. The lining of the cysts in most areas were of flat or cuboidal epithelium and devoid of cellular atypia. The lining epithelium showed proliferative change ranging from atypical ductal hyperplasia to ductal carcinoma in situ, micropapillary type. A microscopic focus of mucinous carcinoma within MLT was also noted. None of the lesions exhibited epithelial reactivity for p53 protein. The patient is alive and well without evidence of disease 54 months after initial treatment. This case supports the concept that MLT encompasses a spectrum of pathologic lesions including benign tumor, atypical ductal hyperplasia, ductal carcinoma in situ, and mucinous carcinoma.
\end{abstract}

Key Words : Breast; Mucocele; Adenocarcinoma, Mucinous

\author{
Ji Shin Lee, Hyung Seok Kim, \\ Jong Jae Jung, Min Cheol Lee* \\ Department of Pathology, Seonam University, \\ College of Medicine, Namwon; Department of \\ Pathology*, Chonnam National University Medical \\ School and Medical Center, Kwangju, Korea
}

Received: 1 June 2000

Accepted : 17 August 2000

Address for correspondence
Ji Shin Lee, M.D.
Department of Pathology, Seonam University,
College of Medicine, 720 Kwangchi-dong,
Namwon 590-170, Korea
Tel: +82.63-620-0352, Fax: +82.63-620-0355
E-mail: jshinlee@hanmail.net

Address for correspondence

Ji Shin Lee, M.D.

Tel: +82.63-620-0352, Fax: +82.63-620-0355

E-mail: jshinlee@nanmail.net

\section{INTRODUCTION}

Mucocele like tumor (MLT) of the breast was first reported by Rosen (1) in 1986 as benign neoplasia analogous to mucocele of the minor salivary gland. This lesion is characterized by mucus-filled cysts lined by flattened epithelium with only a focal tendency to papillary hyperplasia. A nother constant finding is an extrusion of mucin into the surrounding stroma. Subsequent reports identified M LT associated with ductal hyperplasia and carcinoma (2-4). M ore recently, MLT has been considered as a spectrum of pathologic lesions, including benign tumor, atypical ductal hyperpla sia, ductal carcinoma in situ, and mucinous carcinoma (5). In K orea only a few cases of MLT have been reported (6-8). We describe a case of MLT associated with ductal carcinoma in situ and mucinous carcinoma in a 34-yr-old female.

\section{CASE REPORT}

A 34-yr-old female presented with a pal pable mass in the right breast. The mammograph showed an ill-defined and lobulated mass with tiny microcalcifications. Excisional biopsy was done. The specimen measured $2.6 \times 2.0 \times 1.5$ $\mathrm{cm}$ and had a lobulated surface. The cut section revealed multiple aggregated cysts containing gelatinous materials. $\mathrm{H}$ istological examination showed multiple cysts of varying size (Fig. 1). The cysts contained an amorphous mucinous secretion. Extrusion of mucinous material into the surrounding stroma was also observed. The mucinous content in the cysts and in the stroma was positive for periodic acidSchiff with diastase and mucicarmine. The lining of the cysts in most areas were of flat or cuboidal epithelium and devoid of cellular atypia (Fig. 2). The lining epithelium showed proliferative change ranging from atypical ductal hyperplasia to ductal carcinoma in situ, micropapillary type (Fig. 3). A microscopic focus of mucinous carcinoma within MLT was also noted (Fig. 4). N one of the neoplastic lesions were positive for S-100 protein (Zymed, San Francisco, CA, U.S.A., predilute), carcinoembryonic antigen (Zymed, predilute), and p53 protein (Zymed, dilution 1:50).

There was no residual MLT or mucinous carcinoma in the subsequent modified radical mastectomy specimen. Axillary lymph nodes were free of tumor metastasis. The patient is alive and well without evidence of disease 54 months after operation. 


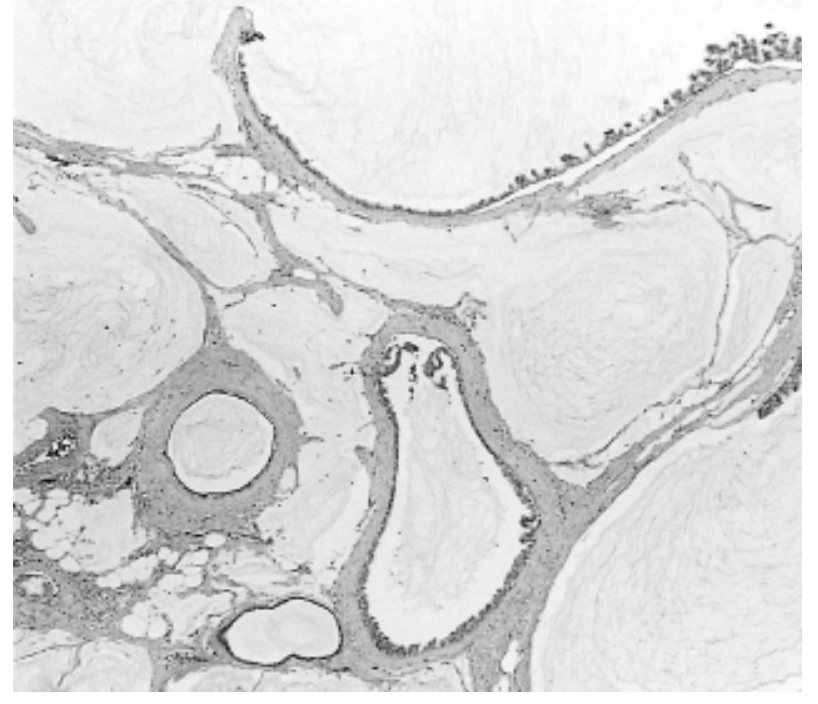

Fig. 1. Mucoele-like tumor with mucin-filled epithelial lined cysts and extravasated mucin in the stroma (H\&E, $\times 40)$.
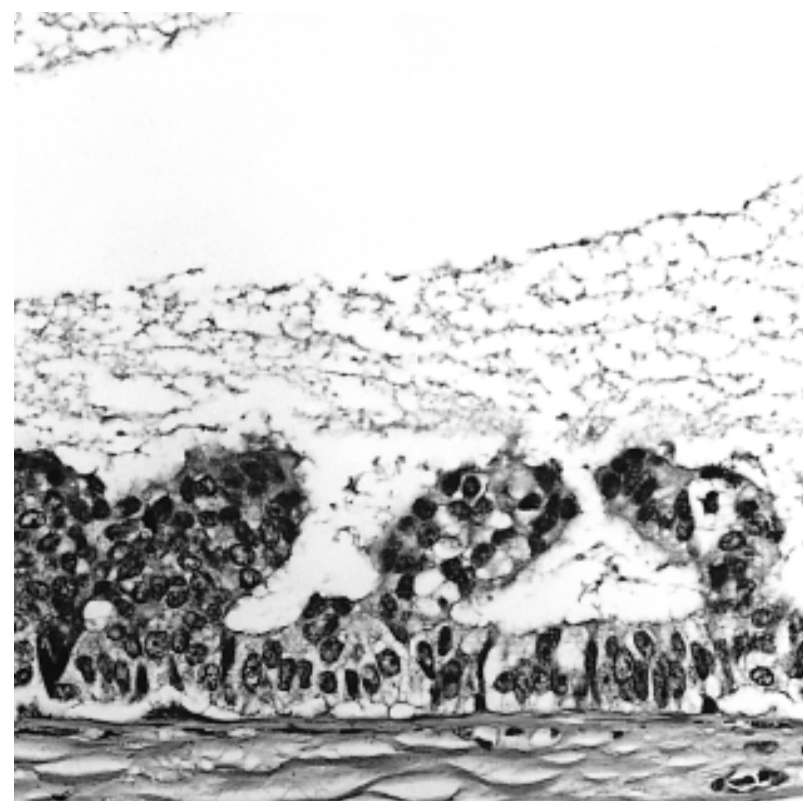

Fig. 3. Mucocele-like tumor with intraductal carcinoma. Ductal carcinoma in situ of micropapillary type is present $(\mathrm{H} \& \mathrm{E}, \times 400)$.

\section{DISCUSSION}

The term MLT of the breast was used by Rosen (1) to describe mucus-filled cysts lined by flattened epithelium with focal areas of hyperplasia often producing a papillary pattern. The extruded mucinous material is commonly pre sent within the stroma. Rosen distinguished MLT from

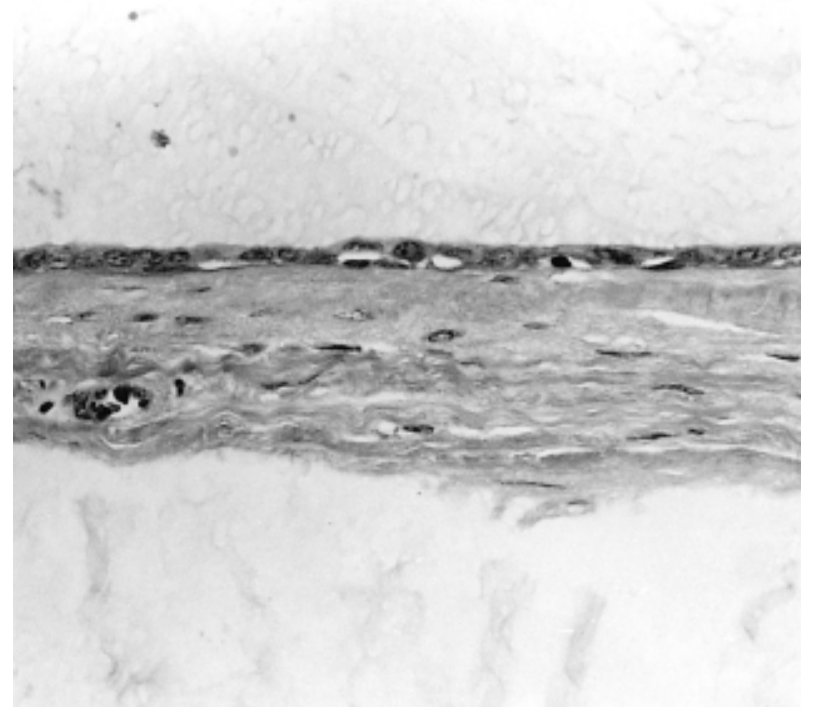

Fig. 2. The lining cells of cysts are usually flat $(H \& E, \times 400)$.

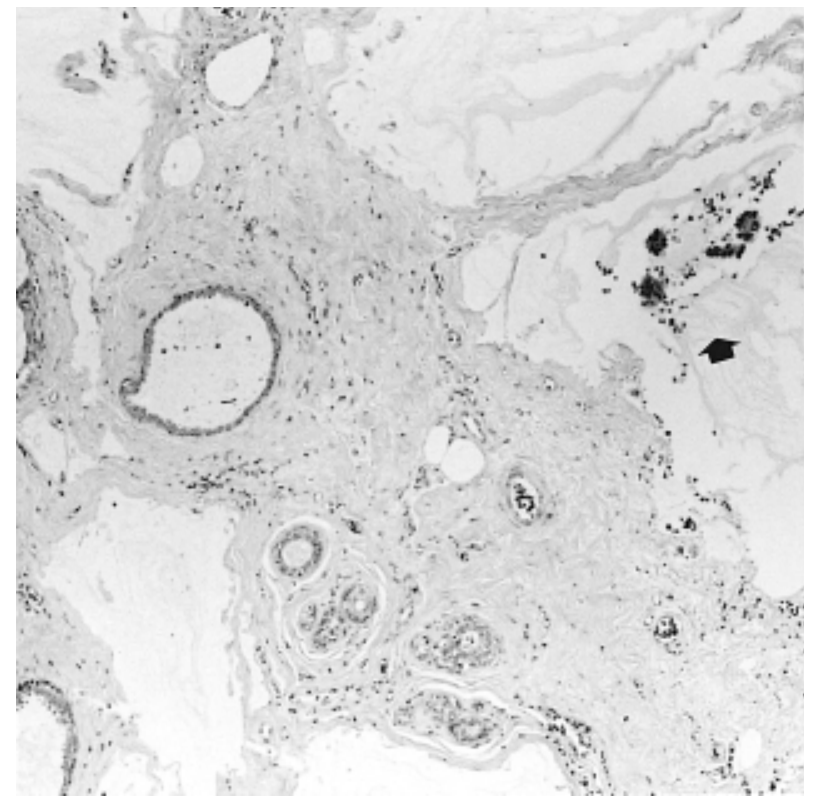

Fig. 4. A microscopic focus of mucinous carcinoma (arrow) is adjacent to the mucocele-like tumor $(H \& E, \times 100)$.

mucinous carcinoma. In contrast to the lack of association with malignancy in Rosen's cases, Ro et al. (2) reported seven cases of MLT associated with atypical ductal hyperplasia or microscopic foci of mucinous carcinoma. The mucin of MLT was identical with that of mucinous carcino$\mathrm{ma}$, and they suggested that some M LTs may be the early form of mucinous carcinoma of the breast. Subsequent 
reports identified MLT associated with ductal hyperplasia or mucinous carcinoma $(3,4)$. In this case all these morphological features of MLT were identified. In addition, ductal carcinoma in situ and mucious carcinoma wereal so observed.

Weaver et al. (9) suggested that M LT and mucinous carcinoma of the breast may represent the two ends of pathological spectrum of mucinous lesions of the breast. M ore recently, MLT was considered as a spectrum of pathologic lesions including benign tumor, atypical ductal hyperplasia, ductal carcinoma in situ, and mucinous carcinoma (5). It is important, therefore, to exclude the possibility of carcinoma by examining adequate tissue samples when MLT is found in a breast biopsy.

$\mathrm{H}$ amele-Bena et al. (10) compared the clinical features of benign and malignant MLTs. Malignant MLT had ductal carcinoma in situ or mucinous carcinoma. There were no appreciable differences in age, tumor size, or laterality between patients with benign MLT or malignant one, although MLT with carcinoma had coarse calcification more often than benign MLT. All of the patients were alive without evidence of disease In this case tiny microcalcification was mammographically detected. The neoplastic epithelium of benign and malignant lesion was negative for p53 protein. The patient is alive and well after the follow-up of 54 months. Our case supports the concept that MLT encompasses a spectrum of pathologic lesions including benign tumor, atypical ductal hyperplasia, ductal carcinoma in situ, and mucinous carcinoma and MLT with mucinous carcinomais a low-gradeneoplasm of the breast.

The pathogenesis of MLT of the breast is uncertain, but excess production of mucinous secretion or ductal obstruction may bethe contributing factors $(1,2)$.

The differential diagnosis of MLT includes cystic hypersecretory hyperplasia and cystic hypersecretory duct carcinoma of the breast (11). H owever, these lesions show cystically dilated ducts containing a homogeneous secretion. But these lesions are not associated with extravasated mucinous material into the stroma, which is a typical feature of M LT.

\section{REFERENCES}

1. Rosen PP. Mucocele-like tumors of the breast. Am J Surg Pathol 1986; 10: 464-9.

2. Ro JY, Sneige N, Sahin AA, Silva EG, del Junco GW, Ayala AG. Mucocelelike tumor of the breast associated with atypical ductal hyperplasia or mucinous carcinoma. Arch Pathol Lab Med 1991; 115: 137-40.

3. Fisher CJ, Millis RR. A mucocele-like tumour of the breast associated with both atypical ductal hyperplasia and mucoid carcinoma. Histopathology 1992; 21: 69-71.

4. Kulka J, Davies JD. Mucocele-like tumours: more associations and possibly ductal carcinoma in situ? Histopathology 1993; 22: 511-2.

5. Yeoh GP, Cheung PS, Chan KW. Fine-needle aspiration cytology of mucocelelike tumors of the breast. Am J Surg Pathol 1999; 23: 552-9.

6. Kim HS, Park JM, Ji EK, Gong GY, Ahn SH. Mucocele-like tumor of the breast: a case report. J Korean Radiol Soc 1999; 41: 607-9.

7. Kim DS, Lee SJ, Hwang MS, Bae YK, Lee JK, Kwun KB. Mucocele-like tumor. In: Disease of the breast: case reviews. 1st ed. Taegu: Sae Han Press, 2000; 46-9.

8. Jang KY, Park HS, Chung MJ, Moon WS, Kang MJ, Lee DG. Mucocelelike tumor of the breast associated with atypical ductal hyperplasia and invasive lobular carcinoma (abstract). Korean J Pathol 1999; 33: 10: 788.

9. Weaver MG, Abdul-Karim FW, Al-Kaisi N. Mucinous lesions of the breast. A pathologic continuum. Pathol Res Proc 1993; 189: 873-6.

10. Hamele-Bena D, Cranor ML, Rosen PP. Mammary mucocele-like lesions: benign and malignant. Am J Surg Pathol 1996; 20: 1081-5.

11. Colandrea JM, Shmookler BM, O’Dowd GJ, Cohen MH. Cystic hypersecretory duct carcinoma of the breast: report of a case with fine-needle aspiration. Arch Pathol Lab Med 1988; 112: 560-3. 